\title{
Cutting-Edge Strategies in Massive Transfusion in Patients of Obstetric Hemorrhage
}

\author{
Ritcha Saxena ${ }^{1^{*}}$, Ananya Saxena ${ }^{2},{\text { Ritwik } \text { Raj }^{3} \text { and Terrence Marcelle }}^{4}$ \\ ${ }^{1}$ Department of Pathology and Transfusion Medicine, All Saints University School of Medicine, Roseau, Dominica \\ ${ }^{2}$ All Saints University School of Medicine, Roseau, Dominica \\ ${ }^{3}$ Department of Biomedical Engineering, Delhi Technological University, Delhi, India \\ ${ }^{4}$ Department of Obstetrics \& Gynecology, All Saints University School of Medicine, Roseau, Dominica
}

*Corresponding author: Ritcha Saxena, Department of Pathology, All Saints University School of Medicine, Roseau, Dominica, Tel: +1-767-2777036; Email:ritcha.saxena@yahoo.in

Received: November 15, 2016; Accepted: December 09, 2016; Published: December 16, 2016

Copyright: $\odot 2016$ Saxena R, et al. This is an open-access article distributed under the terms of the Creative Commons Attribution License, which permits unrestricted use, distribution, and reproduction in any medium, provided the original author and source are credited.

\begin{abstract}
Obstetric hemorrhage is a life-threatening complication which may occur without warning, predictive signs and symptoms, and even in absence of predisposing conditions. It is a major cause of maternal mortality and morbidity almost invariably among all human races. One of the most important strategies in the control of obstetric hemorrhage is hemostatic resuscitation. The speed with which obstetric hemorrhage occurs makes it lifethreatening, but thankfully, it can be successfully managed with blood transfusion protocol based management. Resuscitation of massive hemorrhage has shifted towards the earlier administration of higher doses of fresh frozen plasma (FFP) and reducing serious complications and mortality by limiting the conventional use of crystalloids and colloids. In this article, we explored the leading-edge strategy of use of fibrinogen concentrates, cryoprecipitates, Tranexamic acid and prothrombin complex concentrates, apart from fresh frozen plasma as a promising alternative for obstetric resuscitation and for minimizing the risks and complications of obstetric hemorrhage.
\end{abstract}

Keywords: Fibrinogen concentrates; Cryoprecipitates; Tranexamic acid; Prothrombin complex concentrates; Fresh frozen plasma; Recombinant activated factor VII; Hemostatic resuscitation

\section{Introduction}

Hemorrhage is a leading cause of potentially avertable death. Obstetric hemorrhage is one of the most common causes of shock and is a significant contributor to maternal mortality throughout the world. High mortality in obstetric hemorrhagic shock is mainly because of a deadly combination of coagulopathy, acidosis and hypothermia. Massive blood transfusion protocols enable adequate blood circulation and hemostasis and thus prevent high mortality from obstetric hemorrhage. Even though there is no universal definition of massive blood loss, it can nevertheless be described as: i) blood loss exceeding circulating blood volume within a period of $24 \mathrm{~h}$, ii) blood loss of 50\% of circulating blood volume within a period of $3 \mathrm{~h}$, iii) blood loss exceeding $150 \mathrm{ml} / \mathrm{min}$, or iv) blood loss that necessitates plasma and platelet transfusion [1]. When critical bleeding occurs, a chief officer a person in charge, is appointed, who carries out the most important task of medical assessment of the hemodynamic status of a patient and the most likely course of ongoing bleeding, and then declares an emergency. To effectively deal with critical bleeding in obstetric emergencies, effective communication among responsible staff is crucial, especially between obstetricians and nurses in the obstetric ICU, and between blood transfusion services and a blood bank.

\section{Definition of Massive Blood Transfusion}

Massive transfusion is defined, in adults, as replacement of greater than one blood volume in $24 \mathrm{~h}$ or greater than $50 \%$ of blood volume in
$4 \mathrm{~h}$ (adult blood volume is approximately $70 \mathrm{ml} / \mathrm{kg}$ ). In children, it is defined as transfusion of greater than $40 \mathrm{ml} / \mathrm{kg}$ (blood volume in children over 1 month old is approximately $80 \mathrm{ml} / \mathrm{kg}$ ). Thus, the traditional definition of massive transfusion is 20 units' RBCs in $24 \mathrm{~h}$, which corresponds to approximately 1 blood volume in a $70 \mathrm{~kg}$ patient [2]. Another definition of massive blood transfusion is the transfusion of 10 units or more units of RBCs in $24 \mathrm{~h}$ [3].

Other definitions include use of 50 units of blood components in 24 $\mathrm{h}$; use of 6 units RBCs in $12 \mathrm{~h}$ and so on. Thus, there is a high discrepancy in defining massive transfusion which results in great inconsistency in massive transfusion protocols (MTP).

\section{Massive transfusion protocols (MTPs)}

In the past, patients with massive bleeding were initially treated with colloids and crystalloids. Use of blood products was guided by laboratory results. As a result, blood loss continued, due to delay in laboratory turnaround time and dilutional coagulopathy. Latest approach for resuscitation of patients with massive hemorrhage has advanced from reactive, supportive treatment with crystalloid, packed RBCs, and laboratory report based on use of coagulation factors, to an active and urgent use of proactive standardized protocols called MTPs. MTPs are intended towards control of lethal consequences of massive transfusion, namely coagulopathy, acidosis and hypothermia. MTPs are activated by a clinician in response to massive bleeding by and largely it is activated after transfusion of nearly 4 units to 10 units. MTPs have a predefined ratio of RBCs, FFP/cryoprecipitate and platelets units (random donor platelets) in each unit (e.g. 1:1:1 or 2:1:1 ratio) for transfusion $[4,5]$. Over the last decade, transfusion therapy is targeted towards achieving more balanced transfusion ratios while making efforts to reconstitute the whole blood, which has resulted in 
decreased transfusion amounts, reduced complications, and enhanced chances of survival [6-10].

However, there are certain disadvantages linked with MTPs. Since MTPs are not standardized, there exist some controversies regarding the optimum ratios of RBCs: FFPs: Platelets [11-13].

\section{Complications following massive blood transfusion}

Complications related to massive blood transfusion include fluid overload, coagulopathy, acidosis, thrombocytopenia, and hyperkalemia. There are also certain complications that are secondary to volume resuscitation. Inadequate resuscitation leads to lactic acidosis, disseminated intravascular coagulopathy, and systemic inflammatory response, and thereby, multi-organ dysfunction.

Overenthusiastic resuscitation may also lead to circulatory overload in patients with hemorrhagic shock, in cases where crystalloids and colloids are used initially and later replaced with blood and blood products. Patients who are transfused with crystalloids and get packed red blood cell replacement may suffer with the dilution of coagulation factors, which ends up in dilutional coagulopathy [14-16]. This may further be complicated by hypothermia and acidosis which further exacerbate coagulation dysfunction, initiating a vicious circle of dilutional coagulopathy.

Some complications result due to large amount of stored blood that is citrate toxicity, which can worsen the acidosis because of the development of hypocalcemia, and hypomagnesemia in the patient. The former may result in myocardial depression.

\section{Hemostatic Resuscitation in Obstetric Hemorrhage}

Obstetric hemorrhage remains a leading cause of maternal mortality worldwide. In 2005, hemorrhage was the third leading cause of maternal death due to obstetric complications in the United States [17]. The direct pregnancy related maternal mortality rate in the United States is approximately 7 to 10 women per 100,000 live births and approximately $8 \%$ of these deaths are caused by obstetric hemorrhage [18]. Increased rates of cesarean section have resulted in increased occurrence of placental abnormalities that include both placenta previa and accreta, making peripartum hemorrhage as one of the most important potential causes for maternal mortality [19]. The high incidence of obstetric hemorrhage in the developing countries of the world is more likely reflected by its rates for expectant management and the lack of widespread availability of medicines used in obstetric procedures. Lack of availability of blood transfusion services, anesthetic services, and operating abilities also have great implications [20]. Thus, hemorrhage comprises the most common type of shock in obstetric practice.

Obstetric hemorrhage patients require aggressive measures to restore and maintain the circulating blood volume. MTPs are required to treat such patients, which involve multidisciplinary approach, including obstetricians, anesthesiologists, hematologists, and blood bank personnel [21].

Formal assessment of obstetric hemorrhage is made by observing the amount of bleeding and the patient's vital signs initially legs are raised, oxygen is administered, and resuscitation is started with crystalloids. Blood loss of up to $1500 \mathrm{ml}$ in an otherwise healthy patient with obstetric hemorrhage can usually be managed by crystalloid infusion alone in case the cause of bleeding is arrested but it is difficult to assess the exact amount of blood loss. Overenthusiastic crystalloid resuscitation should be avoided since excessive quantities of crystalloids have been associated with interstitial edema, which can involve vital organs like brain, heart and lungs, leading to grave consequences [22]. Interstitial edema due to an increased hydrostatic pressure may lead to abdominal compartment syndrome, which may also worsen renal perfusion. Also, obstetric hemorrhage patients may have DIC resulting in renal injury and overzealous crystalloid administration in such patients may further aggravate renal damage by inducing interstitial kidney edema with renal vein obliteration [23]. Knowing that chloride induces renal vasoconstriction, administration of chloride rich fluids like $0.9 \%$ saline can further deteriorate renal function [24]. A special precaution in obstetric hemorrhage is to allow hypotension with systolic blood pressures between $80 \mathrm{mmHg}$ and 100 $\mathrm{mmHg}$ to decrease blood loss before the surgical intervention [25].

Recent studies suggest that acquired fibrinogen deficiency may be the major coagulation abnormality associated with obstetric bleeding which may be compounded by dilutional coagulopathy and hyperfibrinolysis [26,27]. In obstetric hemorrhage, tissue hypoperfusion an increases the expression of thrombomodulin on endothelial cells. This receptor interacts with thrombin, leading to activation of the protein $C$ pathway, which irreversibly inhibits factors $\mathrm{Va}$ and VIIIa and an increase fibrinolysis by inhibiting plasminogen activator inhibitor 1 [28]. Uterine atony, placental abruption, and placenta accreta also contribute to an increased fibrinolytic activity in obstetric hemorrhage [25].

\section{Current trends in hemostatic resuscitation}

Hemostatic resuscitation has emerged as a revolutionary approach and the main idea of this approach is to restrict the administration of crystalloids and encouraging blood products for resuscitation [29]. Physiologically, hemodynamic compensatory mechanisms maintain vital organ perfusion till about $30 \%$ total blood volume loss [30]. Since it is difficult to gauge the amount of blood loss in obstetric hemorrhage, using blood products becomes the keystone of hemostatic resuscitation. Thus, the MTPs play a vital role in hemostatic resuscitation. MTPs provides early access to red blood cells, plasma, and platelets $(6: 4: 1)$ for patients experiencing severe obstetric hemorrhage [31].

\section{Fresh frozen plasma (FFP) and platelets}

Earlier, previously healthy women (with no preexisting disorder of hemostasis) with obstetric hemorrhage required an initial blood work - a coagulation screen and platelet count. After getting laboratory reports, the ratio of packed RBCs (PRBCs), platelets and FFP to be administered was decided. Nowadays, rapid transfusion of PRBCs in a 1:1:1 ratio with FFP and platelets is carried out to replenish the lost oxygen carrying capacity as well as circulating volume [32,33]. A rapid infusion set with an integrated warmer or a pressure cuff may be used to increase the infusion rate. Complications like dilutional coagulopathy, interstitial edema, and renal complications can be thus minimized in these patients. A recent clinical trial found no indication of adverse reactions related to increased ratios of FFP:PRBC [34].

A number of studies advocate the addition of $1 \mathrm{U}$ of FFP for every 5 $\mathrm{U}$ of PRBCs for patients who require continued transfusion. Thrombocytopenia is likely after 1.52 times the blood volume has been replaced. The aim is to keep the platelet count more than $50 \times 10^{9} / \mathrm{L}$ by using platelet transfusion. Each unit of platelets increases the platelet count by approximately $10 \times 10^{9} / \mathrm{L}$ (Platelets are usually given in packs 
of $56 \mathrm{U}$ ). If bleeding continues and the platelet count is less than $50 \times$ $10^{9} / \mathrm{L}, 10 \mathrm{U}$ to $12 \mathrm{U}$ is administered initially. Ideally, the patient should have a platelet count $>50 \times 10^{9} / \mathrm{L}$, fibrinogen $>50 \mathrm{e} 100 \mathrm{mg} / \mathrm{dL}$, temperature $>32^{\circ} \mathrm{C}(\mathrm{pH}>7.2)$, and normal ionized calcium, prior to administration [35].

\section{Use of recombinant activated factor VII (rFVIIa)}

Recombinant activated factor VII (rFVIIa) was originally used in the treatment of hemorrhage in patients with hemophilia $\mathrm{A}$ or hemophilia B in whom alloantibodies were formed against factors VIII or IX after replacement therapy [36]. Usage of Recombinant Activated factor VII in cases of obstetric bleeding has made notable advances in the last more than one decade since it was first used by Moscardo et al. [37], who reported the original case in 2001. However, in a study, researchers found that there is a larger risk of arterial thrombosis in patients who receive recombinant activated factor VII [38].

It seems that routine use of factor VIIa in massive blood transfusion in obstetric hemorrhage can hardly be justified, mainly because of its adverse effects, high cost and lack of survival benefits.

\section{Role of fibrinogen and cryoprecipitates}

In the United States, most of the fibrinogen replacement is done in the form of cryoprecipitates. Fibrinogen levels are generally higher in pregnancy (they reach up to $500 \mathrm{mg} / \mathrm{dl}$ ), and therefore, low levels of fibrinogen characterize a more severe coagulopathy compared with non-pregnant individuals [39]. In case of obstetrical hemorrhage, a serum fibrinogen level below $200 \mathrm{mg} / \mathrm{dl}$ had a positive predictive value for progression to severe hemorrhage [40].

Fibrinogen is vital in clotting cascade by serving as the substrate for thrombin to generate fibrin and also by interacting with the glycoprotein IIb/IIIa on the platelet surface [41]. To achieve specific fibrinogen levels is now considered an important target during massive transfusion. Cryoprecipitate provides a more concentrated form of fibrinogen and other clotting factors (VIII, XIII, von Willebrand factor) and is faster to prepare in the blood bank. It is commonly given $10 \mathrm{U}$ in doses, which is expected to raise the serum fibrinogen by 100 $\mathrm{mg} / \mathrm{dl}$ [42]. It is also helpful immediately before any surgical intervention in patients with abnormal coagulation test results. The use of heparin and anti-fibrinolytic therapy is not recommended in women with DIC of obstetric origin. The goal is to maintain a fibrinogen level of at least $150 \mathrm{mg} / \mathrm{dl}$ to $200 \mathrm{mg} / \mathrm{dl}$ during obstetrical hemorrhage.

Each unit of cryoprecipitate will increase the serum fibrinogen by 10 $\mathrm{mg} / \mathrm{dl}$. Cryoprecipitate contains a higher concentration of fibrinogen than FFP. However, like FFP, it always carries a risk of viral transmission. Another disadvantage is the large amount of time required to thaw cryoprecipitate.

Fibrinogen concentrate, which is produced from pooled human plasma using the Cohn/Oncley cryoprecipitation procedure, has emerged as an effective agent in recent years since the concentration of fibrinogen in it is standardized, the product is stored as a lyophilized powder at room temperature, and can be reconstituted concretely and in less time with sterile water and infusion volumes are low, allowing for rapid administration avoiding delays in thawing and cross matching [43]. The safety profile of fibrinogen concentrate is better because viral inactivation and removal of multiple antigens and antibodies is part of the manufacturing process, and hence, risk of viral transmission is greatly reduced [44].
The most widely used fibrinogen concentrate is Hemocomplettan [45]. A number of clinical studies show that this fibrinogen concentrate is able to improve clotting and lower blood loss during obstetric hemorrhage [46,47].

Thus, administration of fibrinogen supplementation can be a safe, quick and effective measure of controlling obstetric hemorrhage.

\section{Tranexamic acid (TA)}

Tranexamic acid (TA) is another anti-fibrinolytic agent which is widely used for prevention and treatment of obstetric hemorrhage. Various clinical trials have shown that TA can decrease blood loss more than $500 \mathrm{ml}$, and this impact was more marked in vaginal deliveries. In obstetric hemorrhage the use of TA has been seen to be associated only with mild side effects like diarrhea, nausea and vomiting, and so far, there is no evidence that could suggest the correlation between the use of TA and increased risk of thrombotic events [48].

Studies have shown a reduction of blood loss in peripartal hemorrhage with the use of TA [49]. Some studies have also described that there has been significant reduction of postpartal hemorrhage with high doses of TA [50]. The use of tranexamic acid is advised in cases of refractory atonic bleeding or persistent trauma-related bleeding [51].

\section{Prothrombin complex concentrates}

Prothrombin complex concentrates (PCC) seems to have a significant role in achieving hemostasis in patients with obstetric hemorrhage. PCC is a combination of clotting factors II, VII, IX and X, and protein $\mathrm{C}$ and $\mathrm{S}$, prepared from fresh-frozen plasma. It has come to be widely used in prophylaxis and treatment of patients with hemorrhage who have vitamin $\mathrm{K}$ deficiency, congenital deficiency of clotting factors and liver disease [52]. It is also used as an alternative to fresh frozen plasma in case of massive hemorrhage due to overdose of anti-coagulants. Previously PCC was also used in obstetric hemorrhage patients where acquired and congenital deficiencies of clotting factors were resolved [53,54].

A very recent study has shown that in patients with vitamin $\mathrm{K}$ antagonists-related intra-cranial hemorrhage PCC is superior to FFP with respect to normalization of international normalized ratio (INR), and thus, smaller hematoma expansion results [55].

However, in patients with obstetric hemorrhage, role of PCC is not quite proven, and, therefore, it should not be used as base treatment alternative, in patients with normal clotting factors assay but in patient's non-responsive to massive blood transfusion protocols, it may be used as an alternative if all other options have been exhausted.

\section{Conclusion}

Poor quantification of blood loss, lack of step-wise progression and poor utilization of blood products are issues of utmost importance in cases of obstetric hemorrhage. MTPs prevent mortality from hemorrhagic shocks, with their precision improving day-by-day by involving a multidisciplinary approach - which provides for timely identification and proper intervention, as well as prompt administration of blood products. In obstetric hemorrhage, emergence of novel strategies like use of TA, fibrinogen concentrates and prothrombin complex concentrates have not only improved the safety profile but also reduced the mortality rates. MTPs need to be revised 
continuously so as to enable the implementation of a well-accepted approach to a clinical problem of paramount significance and thereby improving outcomes, striving towards perfection.

\section{References}

1. Hellstern P, Haubelt H (2002) Indications for plasma in massive transfusion. Thromb Res 107: S19-S22.

2. http://www.transfusion.com.au/disease_therapeutics/transfusion

3. Repine TB, Perkins JG, Kauvar DS, Blackborne L (2006) The use of fresh whole blood in massive transfusion. J Trauma 60: S59-S69.

4. Nunez TC, Young PP, Holcomb JB, Cotton BA (2010) Creation, implementation, and maturation of a MTPs for the exsanguinating trauma patient. J Trauma 68: 1498-1505.

5. O'Keeffe T, Refaai M, Tchorz K, Forestner JE, Sarode R (2008) A massive transfusion protocol to decrease blood component use and costs. Arch Surg 143: 686-690.

6. Ho AM, Karmakar MK, Dion PW (2005) Are we giving enough coagulation factors during major trauma resuscitation? Am J Surg 190: 479-484.

7. Robinson BR, Cotton BA, Pritts TA, Branson R, Holcomb JB, et al. (2013) Application of the Berlin definition in PROMMTT patients: the impact of resuscitation on the incidence of hypoxemia. J Trauma Acute Care Surg 75: S61-S67.

8. Holcomb JB, Wade CE, Michalek JE, Chisholm GB, Zarzabal LA, et al. (2008) Increased plasma and platelet to red blood cell ratios improves outcome in 466 massively transfused civilian trauma patients. Ann Surg 248: 447-458.

9. Johansson PI, Sørensen AM, Larsen CF, Windeløv NA, Stensballe J, et al. (2013) Low hemorrhage-related mortality in trauma patients in a level I trauma center employing transfusion packages and early thromboelastography-directed hemostatic resuscitation with plasma and platelets. Transfusion 53: 3088-3099.

10. Borgman MA, Spinella PC, Perkins JG, Grathwohl KW, Repine T, et al. (2007) The ratio of blood products transfused affects mortality in patients receiving massive transfusions at a combat support hospital. J Trauma 63 : 805-813.

11. Pieracci FM, Kashuk JL, Moore EE (2012) Postinury hemotherapy and hemostasis. (7th edn), McGraw-Hill, New York, USA. pp: 216-235.

12. Kelly JM, Callum JL, Rizoli SB (2013) 1:1:1-warranted or wasteful? even where appropriate, high ratio transfusion protocols are costly: early transition to individualized care benefits patients and transfusion services. Expert Rev Hematol 6: 631-633.

13. Nascimento B, Callum J, Tien H, Rubenfeld G, Pinto R, et al. (2013) Effect of a fixed-ratio (1:1:1) transfusion protocol versus laboratory-resultsguided transfusion in patients with severe trauma: a randomized feasibility trial. CMAJ 185: E583-E589.

14. de Jonge E, Levi M (2001) Effects of different plasma substitutes on blood coagulation: A comparative review. Crit Care Med 29: 1261-1267.

15. Niemi TT, SuojarantaYlinen RT, Kukkonen SI, Kuitunen AH (2006) Gelatin and hydroxyethyl starch, but not albumin, impair hemostasis after cardiac surgery. Anesth Analg 102: 998-1006.

16. FengerEriksen C, AnkerMøller E, Heslop J, Ingerslev J, Sørensen B (2005) Thrombelastographic whole blood clot formation after ex vivo addition of plasma substitutes: Improvements of the induced coagulopathy with fibrinogen concentrate. Br J Anaesth 94: 324-329.

17. Kung HC, Hoyert DL, Xu J, Murphy SL (2008) Deaths: final data for 2005 Natl Vital Stat Rep 56: 1-120.

18. Berg CJ, Atrash HK, Koonin LM, Tucker M (1996) Pregnancy related mortality in the United States, 1987-1990. Obstet Gynecol 88: 1617.

19. Kwee A, Bots ML, Visser GH, Bruinse HW (2006) Emergency peripartum hysterectomy: a prospective study in The Netherlands. Eur J Obstet Gynecol Reprod Biol 124: 187-192.
20. Murray CJ, Lopez AD (1998) Health Dimensions of Sex and Reproduction. Harvard University Press, Boston, Massachusetts, USA. p: 1724 .

21. Stainsby D, MacLennan S, Hamilton PJ (2000) Management of massive blood loss: a template guideline. Br J Anaesth 85: 487-491.

22. Levi M, Ed J (2007) Clinical relevance of the effects of plasma expanders on coagulation. Semin Thromb Hemost 33: 810-815.

23. Herrler T, Tischer A, Meyer A, Sergej F, Markus G, et al. (2010) The intrinsic renal compartment syndrome: new perspectives in kidney transplantation. Transplantation 89: 4046.

24. Yunos NM, Bellomo R, Story D, Kellum J (2010) Benchtobedside review: chloride in critical illness. Crit Care 14: 226.

25. Ickx BE (2010) Fluid and blood transfusion management in obstetrics. Eur J Anaesthesiol 27: 1031-1035.

26. Solomon C, Collis RE, Collins PW (2012) Haemostatic monitoring during postpartum haemorrhage and implications for management. $\mathrm{Br} \mathrm{J}$ Anaesth 109: 851-863.

27. Rossaint R, Bouillon B, Cerny V, Coats TJ, Duranteau J, et al. (2010) Management of bleeding following major trauma: An updated European guideline. Crit Care 14: R52.

28. Brohi K, Cohen MJ, Davenport RA (2007) Acute coagulopathy of trauma: mechanism, identification and effect. Curr Opin Crit Care 13: 680685.

29. John BH, Charles EW, Joel ME, Gary CB, Lee Ann Z, et al. (2008) Increased plasma and platelet to red blood cell ratios improves outcome in 466 massively transfused civilian trauma patients. Ann Surg 248: 447-458.

30. Miller RD (2009) Transfusion therapy. In: Miller RD, editor. Miller's Anesthesia. (7th edn), Churchill Livingstone, Philadelphia, Pennsylvania, USA. pp: 1739-1766.

31. Gutierrez MC, Goodnough LT, Druzin M, Butwick AJ (2012) Postpartum hemorrhage treated with a MTPs at a tertiary obstetric center: a retrospective study. Int J of Obstric Anesthesia 21: 230-235.

32. Kutcher ME, Kornblith LZ, Narayan R, Curd V, Daley AT, et al. (2013) A paradigm shift in trauma resuscitation: Evaluation of evolving massive transfusion practices. JAMA Surg 148: 834-840.

33. Wafaisade A, Maegele M, Lefering R, Braun M, Peiniger S, et al. (2011) High plasma to red blood cell ratios are associated with lower mortality rates in patients receiving multiple transfusion $(4 \leq$ red blood cell units $<10$ ) during acute trauma resuscitation. J Trauma 70: 81-88.

34. Holcomb JB, Tilley BC, Baraniuk S, Fox EE, Wade CE, et al. (2015) Transfusion of plasma, platelets, and red blood cells in a 1:1:1 vs. a 1:1:2 ratio and mortality in patients with severe trauma: The PROPPR randomized clinical trial. JAMA 313: 471-482.

35. Spahn DR, Cerny V, Coats TJ, Duranteau J, Fernández-Mondéjar E, et al. (2007) Management of bleeding following major trauma: a European guideline. Crit Care 11: R17.

36. Lusher JM, Roberts HR, Davignon G, Joist JH, Smith H, et al. (1998) A randomized, double-blind comparison of two doses of recombinant factor VIIa in the treatment of joint, muscle and mucocutaneous haemorrhages in persons with haemophilia A and B, with and without inhibitors. rFVIIa Study Group. Haemopholia 4: 790-798.

37. Moscardo F, Perez F, de la Rubia J, Balerdi B, Lorenzo JI, et al. (2001) Successful treatment of severe intra-abdominal bleeding associated with disseminated intravascular coagulation using recombinant activated factor VII. Br J Haematol 113: 174-176.

38. Levi M, Levi JH, Andersen HF, Truloff D (2010) Safety of recombinant activated factor VII in randomized clinical trials. N Engl J Med 363: 1791-1800.

39. Spahn DR, Bouillon B, Cerny V, Coats TJ, Duranteau J, et al. (2013) Management of bleeding and coagulopathy following major trauma: an updated European guideline. Crit Care 17: R76.

40. Charbit B, Mandelbrot L, Samain E, Baron G, Haddaoui B, et al. (2007) The decrease of fibrinogen is an early predictor of the severity of postpartum hemorrhage. J Thromb Haemost 5: 266-273. 
Citation: Saxena R, Saxena A, Raj R, Marcelle T (2016) Cutting-Edge Strategies in Massive Transfusion in Patients of Obstetric Hemorrhage. J Gen Pract (Los Angel) 4: 280. doi:10.4172/2329-9126.1000280

Page 5 of 5

41. Franchini M, Lippi G (2012) Fibrinogen replacement therapy: a critical review of the literature. Blood Transfus 10: 237.

42. Nascimento B, Goodnough LT, Levy JH (2014) Cryoprecipitate therapy. Br J Anaesth 113: 922-934.

43. Fenger-Erikson C, Ingerslev J, Sørensen B (2009) Fibrinogen concentrate - a potential universal haemostatic agent. Expert Opin Biol Ther 9: 1325-1333.

44. Pereira A (2007) Cryoprecipitate versus commercial fibrinogen concentrate in patients who occasionally require a therapeutic supply of fibrinogen: risk comparison in case of an emerging transfusiontransmitted infection. Haematologia 92: 846-849.

45. Kruez W, Meili E, Peter-Salonen K, Dobrkovská A, Devay J, et al. (2005) Pharmacokinetic properties of apasteurised fibrinogen concentrate Transfus Apher Sci 32: 239-246.

46. Bell SF, Rayment R, Collins PW, Collis RE (2010) The use of fibrinogen concentrate to correct hypofibrinogenemia rapidly during obstetric hemorrhage. Int J Obstet Anesth 19: 218-223.

47. Kikuchi M, Itakura A, Miki A, Nishibayashi M, Ikebuchi K, et al. (2013) Fibrinogen concentrate substitution therapy for obstetric hemorrhage complicated by coagulopathy. J Obstet Gynaecol Res 39: 7706.

48. Novikova N, Hofmeyr G, Cluver C (2015) Tranexamic acid for preventing postpartum haemorrhage. Cochrane Database of Systematic Reviews 6: CD007872.
49. Heesen M, Bohmer J, Klohr S, Rossaint R, van de Velde M, et al. (2014) Prophylactic tranexamic acid in parturients at low risk for post partum hemorrhage: systematic review and meta-analysis. Acta Anaesthesiol Scand 58: 1075-1085.

50. Ducloy-Bouthors AS, Jude B, Duhamel A, Broisin F, Huissoud C, et al. (2011) High-dose tranexamic acid reduces blood loss in postpartum haemorrhage. Crit Care 15: R117.

51. (2012) WHO recommendations for the prevention and treatment of postpartum haemorrhage.

52. Baglin TP, Keeling DM, Watson HG, British Committee for Standards in Haematology (1998) Guidelines on Oral Anticoagulation, 3rd edn. Br J Haematol 101:374-387.

53. Larrain C (1994) Congenital blood coagulation factor X deficiency. Successful result of the use of prothrombin concentrated complex in the control of caesarean section hemorrhage in 2 pregnancies. Revista Medica de Chile 122: 1178-1183.

54. Shobeiri SA, West EC, Kahn MJ, Nolan TE (2000) Postpartum acquired hemophilia (factor VIII inhibitors): a case report and review of the literature. Obstetr Gynecol Surv 55: 729-737.

55. Steiner T, Poli S, Griebe M, Hüsing J, Hajda J, et al. (2016) Fresh frozen plasma versus prothrombin complex concentrate in patients with intracranial haemorrhage related to vitamin $\mathrm{K}$ antagonists (INCH): a randomised trial. Lancet Neurol 15: 566-573. 